\title{
TRANSFORMASI TOKOH DALAM CERITA DEWI KEKAYI SEBAGAI HIPOGRAM CERPEN KEKAYI KARYA OKA RUSMINI (Character Transformation in the Dewi Kekayi Story as Hypogram of Short Story Kekayi by Oka Rusmini)
}

\author{
Alfian Rokhmansyah dan Azizatur Rahma \\ FKIP Universitas Mulawarman, Samarinda, Kalimantan Timur \\ Pos-el: alfian.rokhmansyah@gmail.com \\ Magister Ilmu Sastra, Universitas Gadjah Mada, Yogyakarta \\ Pos-el: liariaziza@gmail.com
}

(Diterima: 9 Desember 2018; Direvisi: 16 Mei 2019; Disetujui: 16 Mei 2019)

\begin{abstract}
This study aims to describe the transformation undergone by the characters in the story of Dewi Kekayi as a hypogram of the short story Kekayi (2017) by Oka Rusmini. Intertextual and hypogram theory are used as the basis of analysis. The research is a qualitative study with a structural approach. In addition, a text comparison method is also used to compare a short story text with its hypogram. Data analysis was done by comparing the motive of the story of Dewi Kekayi in the Ramayana epic as a hypogram and the short story Kekayi as a result of its transformation. The results of this study show that the story of Dewi Kekayi in the Ramayana epic was taken as the hypogram of the short story Kekayi, through the transformation of the story, especially with regard to the characters. In the transformation process, the author incorporates the original story (as a hypogram) into the new story, by adopting the characters in the story of Dewi Kekayi as figures in the short story Kekayi, including Kekayi, Bharata, Dasarata, Kekaya, and Rama. In addition, the author also deconstructs the personality of these characters leading to character trait discrepancies between the story of Dewi Kekayi story and the short story Kekayi.
\end{abstract}

Keywords: hypogram; transformation; intertextual; characterization; Oka Rusmini

\begin{abstract}
Abstrak
Penelitian ini bertujuan untuk mendeskripsikan transformasi tokoh-tokoh dalam cerita Dewi Kekayi sebagai hipogram cerpen Kekayi (2017) karya Oka Rusmini. Teori intertekstual dan hipogram digunakan sebagai dasar dalam analisis. Penelitian ini merupakan penelitian kualitatif dengan pendekatan struktural. Selain itu juga digunakan metode perbandingan teks untuk membandingkan teks cerpen dengan hipogramnya. Analisis data dilakukan dengan membandingkan motif dari cerita Dewi Kekayi dalam epos Ramayana sebagai hipogram dan cerpen Kekayi sebagai hasil tranformasi. Hasil penelitian menunjukkan bahwa cerita Dewi Kekayi dalam epos Ramayana dijadikan hiprogram cerpen Kekayi oleh Oka Rusmini melalui transformasi cerita, khususnya pada tokohtokohnya. Dalam proses transformasi, pengarang mengembangkan cerita asal (sebagai hipogram) di dalam cerita baru, yaitu dengan menjadikan tokoh-tokoh dalam cerita Dewi Kekayi menjadi tokoh-tokoh dalam cerpen Kekayi, seperti tokoh Kekayi, Bharata, Dasarata, Kekaya, dan Rama.
\end{abstract}


Selain itu, pengarang juga mendekonstruksi karakter tokoh-tokoh tersebut yang menyebabkan adanya kontradiksi sifat tokoh dalam cerita Dewi Kekayi dan cerpen Kekayi.

Kata kunci: hipogram; transformasi; intertekstual; tokoh penokohan; Oka Rusmini

\section{PENDAHULUAN}

Ide penciptaan karya sastra tidak hanya sebatas pada persoalan-persoalan yang terjadi saat ini. Ide dapat pula berasal dari karya-karya sastra yang diciptakan sebelumnya, baik karya sastra modern maupun karya sastra lama. Karya sastra lama yang dijadikan ide penciptaan karya sastra baru misalnya cerita wayang. Cerita wayang banyak ditransformasikan dalam pembuatan karya sastra modern-dalam bentuk prosa maupun puisi. Dalam bentuk prosa, novel maupun cerpen yang diadaptasi dari cerita wayang, misalnya Pengakuan Pariyem (Linus Suryadi), Para Priyayi dan Sri Sumarah(Umar Kayam), Durga Umayi dan Burung-Burung Manyar (Y. B. Mangunwijaya), Nostalgia (Danarto), serta Perang (Putu Wijaya) (Nurgiyantoro, 1998: 125).

Oka Rusmini sebagai salah satu pengarang perempuan Indonesia juga mengadopsi cerita wayang sebagai hipogram cerpen yang dihasilkannya. Salah satu cerpen karya Oka Rusmini yang mengadopsi cerita wayang adalah cerpen Kekayi. Cerpen tersebut berisi gambaran kehidupan seorang perempuan Bali bernama Kekayi yang memiliki anak bernama Bharata. Kekayi merupakan anak angkat Raja Kekaya. Dalam cerpen tersebut terdapat dialogdialog antara Kekayi dan Bharata. Selain itu, juga digambarkan posisi Kekayi di dalam kerajaan dan kelakuan saudara angkatnya.

Bagi pembaca karya sastra yang mengerti cerita pewayangan, saat membaca novel Kekayi tersebut akan teringat pada tokoh Dewi Kekayi dalam epos Ramayana, yaitu permaisuri Raja Dasarata dan anak angkat Raja Kekaya. Dalam cerita Dewi Kekayi juga ceritakan bahwa Dewi Kekayi memiliki anak bernama Bharata. Selain itu, dalam cerita juga ada bagian cerita mengenai tujuan yang ingin dicapai oleh Dewi Kekayi.
Hal hal tersebut menunjukkan bahwa cerita dalam cerpen Kekayi yang ditulis oleh Oka Rusmini memiliki keterkaitan dengan cerita Dewi Kekayi dalam epos Ramayana. Dalam cerpen Kekayi juga muncul beberapa nama tokoh pewayangan yang masih berhubungan dengan tokoh Dewi Kekayi, yaitu tokoh Raja Kekaya dan Bharata. Ada pula penyebutan tempat yang ada di dalam cerita Ramayana, yaitu Padnapura.

Menurut Nurgiyantoro (1998: 126) budaya pewayangan merupakan kesenian tradisional yang telah mengakar pada masyarakat Indonesia, khususnya masyarakat Jawa, dan telah menjadi sebuah mitologi. Mitologi pewayangan ini juga telah memengaruhi penulisan sastra Indonesia modern. Di tengah arus modernisasi, karya sastra Indonesia justru banyak yang diorientasikan pada kebudayaan tradisional. Sebagaimana diketahui bahwa cerita wayang merupakan salah satu bentuk warisan budaya tradisional yang masih populer hingga saat ini.

Berdasarkan hal-hal yang telah dipaparkan sebelumnya, penelitian ini difokuskan pada transformasi tokoh-tokoh dalam cerita Dewi Kekayi sebagai hipogram cerpen Kekayi (2017) karya Oka Rusmini. Hal ini didasarkan pada pendapat Nurgiyantoro (2016: 204) yang menyebutkan bahwa perujukan cerita wayang dalam fiksi modern menunjukkan adanya tanggapan pengarang terhadap cerita wayang tersebut. Pengarang dianggap sebagai pembaca aktif-kreatif yang memberikan tanggapan lewat kekuatan imajinasi dan dimanifestasikan ke dalam bentuk karya sastra.

\section{KERANGKA TEORI}

Perubahan dari cerita wayang menjadi bentuk karya sastra modern-khususnya cerpen-merupakan proses transformasi. 
Dalam transformasi dapat terjadi perubahan yang dilakukan oleh pencipta karya baru. Karena adanya adopsi dari karya lama menjadi karya baru, maka terdapat hubungan antara keduanya, atau yang umum disebut dengan intertekstual. Menurut Nurgiyantoro (2016: 204) intertekstual akan terjadi jika sebuah teks sastra merujuk, mengambil, meminjam, mengutip, mengadaptasi, mereaktualisasi, atau mentransformasikan sesuatu dari sumber atau teks lain ke dalam bentuk teks baru.

Intertekstualitas memandang bahwa dalam sebuah teks terdapat teks lain karena sebuah teks tercipta berdasarkan teks-teks yang sudah ada sebagai latarnya. Karya sastra yang ditulis lebih kemudian dapat berlaku sebagai penolakan, pengukuhan, atau perpecahan terhadap karya sastra sebelumnya sehingga ketika meneliti suatu teks, penulis harus menghubungkannya dengan teks-teks lain yang mendasarinya untuk melihat aspek-aspek yang meresap (Sungkowati, 2010: 76).

Kristeva mengungkapkan bahwa any text is constructed as a mosaic of quotations; any textis the absorbtion and transformation of another' setiap teks adalah mozaik kutipankutipan, penyerapan, dan transformasi dari teks lain' (Culler, 2002: 139). Pengarang akan mengambil komponen-komponen dari teks lain untuk diolah dan diproduksi dengan warna penambahan, pengurangan, penentangan, atau pengukuhan sesuai dengan kreatifitasnya, pada saat menulis karya sastra. Setiap teks mengambil hal-hal yang menarik darit eks lain untuk selanjutnya diolah dan ditransformasikan ke dalam karya yang, baik secara sadar maupun tidak sadar. Dari pandangan intertekstual, sebuah teks mengandung berbagai teks di dalamnya (Sungkowati, 2010: 76).

Produksi makna terjadi dalam interteks, yaitu melalui proses oposisi, permutasi, dan transformasi. Penelitian dilakukan dengan cara menemukan hubungan-hubungan makna di antara dua teks atau lebih. Teks-teks yang dikerangkakan sebagai interteks tidak terbatas pada teks yang memiliki persamaan genre.
Interteks memberikan kemungkinan yang seluas-luasnya bagi peneliti untuk menemukan hipogram. Pengkajian interteks dapat dilakukan terhadap novel dengan novel, novel dengan puisi, atau novel dengan mitos. Hubungan yang dimaksudkan tidak semata-mata berupa persamaan, tetapi juga sebaliknya dapat berupa pertentangan, baik sebagai parodi maupun negasi (Inarti, 2016: 84).

Sebuah karya sastra dapat dibaca dalam kaitannya ataupun pertentangan dengan teksteks lain, yang merupakan kisi. Melalui kisi itu, teks dibaca dan diberi struktur dengan harapan agar pembaca memetik ciri-ciri yang menonjol dan memberikan sebuah makna. Pada hakikatnya pembaca dibawa untuk mengacu kepada teks-teks pendahulu sebagai sumbangan pada suatu kode yang memungkinkan efek signifikasi atau pemaknaan yang bermacammacam (Dewi, 2013: 120).

Karya sastra lain yang dijadikan sumber penciptaan karya sastra baru dinamakan hipogram. Riffaterre (1978: 94) menjelaskan bahwa hipogram tidak dapat hadir begitu saja, tetapi muncul melalui proses pemahaman dari si pengarang dan pembaca harus menyimpulkan sendiri. Dalam prinsip intertekstualitas, pembaca akan dibawa untuk memandang teks-teks yang lebih dahulu muncul sebagai sumbangan pada suatu kode yang memungkinkan efek pemaknaan yang bermacam-macam atau signification (Culler, 2005: 103). Penciptaan karya sastra baru tidak akan dapat dilakukan tanpa pengaruh dari teksteks yang sudah ada sebelumnya. Teks-teks lain tersebut dijadikan sebagai acuan. Hal ini tidak berarti karya sastra baru hanya mengambil bagian-bagian teks yang ada sebelumnya sebagai sarana pengacuan, tetapi dapat pula menyimpang dari teks sebelumnya dan mentrasformasikannya dalam teks-teks baru.

Karya sastra baru dapat menentang, menguatkan, atau dapat pula memperbarui gagasan atau ide yang ada dalam karya hipogramnya. Dalam hubungannya dengan konvensi, tiga kemungkinan fungsi yang 
dihadirkan oleh intertekstual, yaitu afirmasi, negasi, atau inovasi (Abdullah, 1991: 105). Negasi artinya adanya perlawanan ide atau gagasan dalam karya sastra baru dari hipogramnya. Afirmasi artinya karya sastra baru hampir sama dengan hipogramnya atau bahkan menjadi penopang yang mengukuhkan ide atau gagasan dari hipogramnya. Sedangkan inovasi artinya karya sastra baru memperbarui ide atau gagasan yang sebelumnya telah dibawa oleh hipogramnya (Al-Mar'ruf, 2005: 80).

Gagasan yang diserap oleh pengarang dalam suatu karya sastra dapat dikenali dengan cara membandingkannya dengan teks hipogram atau teks acuannya. Teks baru yang menyerap dan mentransformasikan teks hipogram disebut teks transformasi (Dewi, 2013: 123; Sungkowati, 2010: 77).

\section{METODE}

Penelitian ini merupakan penelitian kualitatif dengan pendekatan struktural. Mengingat fokus penelitian ini adalah mendeskripsikan transformasi bagian-bagian cerita, maka dalam penelitian ini, digunakan metode perbandingan teks, yaitu akan membandingan teks cerpen dengan hipogramnya. Sumber data utama adalah cerpen Kekayi karya Oka Rusmini yang diterbitkan di harian Jawa Pos edisi Minggu 5 Februari 2017. Sumber data tambahan adalah cerita pewayangan Dewi Kekayi yang termuat dalam epos Ramayana.

Analisis data menggunakan analisis konten. Analisis data dilakukan berdasarkan konsep bahwa konvensi dan gagasan yang diserap dapat dikenali jika membandingkan teks yang menjadi hipogram dengan teks baru. Dalam analisis ini dilakukan perbandingan antara cerita Dewi Kekayi dalam epos Ramayana sebagai hipogram dan cerpen Kekayi sebagai teks tranformasi.

\section{PEMBAHASAN}

Cerpen Kekayi menceritakan seorang perempuan tua bernama Kekayi yang sudah lama mengenyam kehidupan. Dalam cerpen digambarkan bahwa tokoh Kekayi memiliki konflik batin dengan kehidupan yang telah dilaluinya. Pengarang menghadirkan sosok tokoh Kekayi dengan model penceritaan langsung oleh tokoh dalam bentuk percakapan. Tokoh Kekayi digambarkan sebagai seorang perempuan yang mulai merasa muak dengan kehidupan karena ia merasa kehidupan hanya memanfaatkannya. Tokoh Kekayi merasa bahwa dirinya hanya dimanfaatkan oleh lakilaki karena kecantikannya hingga akhirnya dia hamil.

Cerpen tersebut diolah oleh pengarangOka Rusmini-sedemikian rupa hingga menghasilkan gambaran sosok perempuan yang mulai bosan dengan kehidupan, yang dianggap selalu merugikannya. Pengarang mengemas cerita dengan menekankan bahwa perempuan selalu mendapatkan ketertindasan oleh lakilaki. Namun, jika dilihat secara lebih dalam, cerpen Kekayi mengambil 'bahan' dari cerita wayang, yaitu cerita tentang Dewi Kekayi dalam epos Ramayana.

Dalam cerpen Kekayi, transformasi cerita wayang ditemukan pada aspek penokohan, latar, dan alur. Transformasi pada aspek penokohan terlihat pada penggunaan hipogram nama-nama tokoh wayang dalam Ramayana, seperti tokoh Kekayi, Dasarata, Kekaya, Bharata, dan Rama. Akan tetapi, tidak semua nama dari tokoh wayang yang muncul di dalam cerpen disertai dengan transformasi karakternya-hanya 'mencaplok' namanya saja. Transformasi pada aspek latar terlihat pada penggunaan hipogram nama kerajaan, misalnya Kerajaan Padnapura, Sedangkan transformasi pada aspek alur terlihat pada hipogram hubungan kekerabatan dari para tokoh. Hubungan kekerabatan antara Kekayi dan Bharata sebagai ibu dan anak; Kekaya dan Kekayi sebagai ayah dan anak angkat; Dasarata dan Kekayi sebagai suami dan istri; Rama sebagai pemilik kerajaan Padnapura.

Transformasi yang dilakukan oleh pengarang terhadap nama tokoh paling dominan terjadi pada tokoh utama, yaitu Kekayi. Nama 
tokoh utama diambil dari tokoh Dewi Kekayi dalam epos Ramayana. Hal ini dilakukan secara sadar oleh pengarang. Selain itu, penggunaan nama Kekayi sebagai hasil transformasi juga dibarengi dengan hubungan kekerabatan dari tokoh tersebut dalam hipogramnya, yaitu kemunculan tokoh Bharata (sebagai anak), Dasarata (sebagai suami), Kekayi (sebagai ayah), dan tokoh Rama. Namun, pengarang mendekonstruksi cerita dengan melakukan beberapa perubahan pakem terhadap watak tokoh Kekayi, Dasarata, dan saudara angkat Kekayi. Sebaliknya, transformasi alur tidak diubah dan masih dipertahankan oleh pengarang sebagaimana alur di dalam cerita Ramayana.

Dalam cerita Ramayana, Dewi Kekayi digambarkan sebagai anak angkat Prabu Kekaya, Raja Padnapura. Asal usul Dewi Kekayi tersebut ditransformasikan secara utuh oleh pengarang, sebagaimana terlihat pada kutipan berikut ini.

Sejak kecil Kekayi sadar, sebagai anak angkat Raja Kekaya, posisinya sangat lemah. Dia tidak mungkin menjadi ratu, menggantikan Kekaya memimpin Kerajaan Padnapura. Padahal sejak kecil, ketika berumur dua belas tahun, dan diangkat anak oleh Kekaya, Kekayi selalu membayangkan duduk dengan kepala tegak di kursi singgasana Padnapura. Bahkan dia telah mempersiapkan diri untuk menjadi lelaki (Rusmini, 2017).

Pada kutipan di atas, terlihat bahwa pengarang masih mempertahankan pakem asalusul Dewi Kekayi sebagai anak angkat Prabu Kekaya - yaitu raja Kerajaan Padnapura. Akan tetapi, dalamcerita hasiltransformasi, pengarang menggambarkan tokoh Kekayi adalah sosok anak angkat perempuan yang memiliki ambisi untuk menjadi pemimpin Kerajaan Padnapura. Ambisi tersebut telah muncul sejak Kekayi kecil. Perubahan transformasi dari pakem cerita sebenarnya menunjukkan bahwa ada ideologi yang ingin diciptakan oleh pengarang. Perubahan dari pakem cerita Dewi Kekayi juga dimunculkan pada penggambaran tokoh saudara angkat Dewi Kekayi, yaitu Yudhajit.
Dalamceritawayang, Yudhajit merupakan raja dari Kerajaan Padnapura, menggantikan Prabu Kekaya. Yudhajit digambarkan sebagai seorang paman yang baik dan selalu memberikan perhatian terhadap Bharata - anak Dewi Kekayi. Namun, pengarang mengubah pakem mengenai sosok Yudhajit dalam transformasinya. Yudhajit dianggap sebagai sosok raja yang gemar mempermainkan dan melakukan pelecehan terhadap perempuan.

Usaha kerasnya untuk menunjukkan pada Kekaya bahwa dirinya layak diperhitungkan sebagai salah satu calon penguasa sia-sia. Kekaya telah mempersiapkan seorang putra mahkota. Seorang lelaki yang lebih tua dari Kekayi. Putra mahkota yang sejak lahir sadar akan haknya sebagai penguasa. Lelaki bodoh, pemalas, dan sombong! Dia juga memperlakukan para perempuan muda di kerajaan dengan tidak hormat.

Suatu pagi, dia meremas dada Kekayi, menepuk bokongnya sambil tertawa, bersama para pengawal dan saudara-saudara lelakinya. Kekayi menggunakan bagian ujung tanganbagian yang bersentuhan langsung dengan objek - untuk memukul objek. Semakin kecil dan lancip ujung tangan yang digunakan untuk memukul, semakin mudah untuk meremukkan objek. Itu petunjuk dari gurunya. Kekayi pun mempraktikkan dengan riang teknik melumpuhkan lawan itu. Hasilnya, gigi calon raja itu rompal. Tangan kanannya patah. Leher terkilir (Rusmini, 2017).

Kutipan di atas menunjukkan bahwa pengarang menggambarkan tokoh saudara Kekayi-dalam cerpen — sebagai seorang lakilaki bodoh, pemalas, serta sombong. Pengarang juga memberikan gambaran bahwa Kekayi pernah mendapatkan perlakuan burukpelecehan-dari saudara angkatnya tersebut. Selain itu, pada kutipan di atas juga terlihat bahwa pengarang juga 'melanggar' pakem mengenai sosok tokoh wayang perempuan yang lemah lembut. Dalam cerpen digambarkan tokoh Kekayi yang gemar melakukan halhal yang pada umumnya dilakukan laki- 
laki-berkelahi. Penggambaran pelanggaran pakem watak tokoh wayang perempuan juga digambarkan pada kutipan di bawah ini.

Kekayi sejak kecil selalu minta dilatih bela diri, melempar tombak berburu, dan melakukan hal-hal yang biasanya tidak dilakukan anak perempuan. Kekayi akan marah besar jika Kekaya menolak permintaannya untuk bertarung dengan anak lelaki. Di setiap pertarungan Kekayi akan berpakaian seperti lelaki, sehingga para petarung tidak melihatnya sebagai perempuan. Di setiap pertarungan Kekayi selalu mudah menaklukkan lawan (Rusmini, 2017).

Dalam cerita Dewi Kekayi juga diceritakan sosok Dasarata, yaitu suami Dewi Kekayi. Dia adalah raja kerajaan Ayodya. Dewi Kekayi merupakan istri kedua Dasarata. Pertemuan Dasarata dan Dewi Kekayi yaitu pada saat terjadi peperangan. Dewi Kekayi menyelamatkan nyawa Dasarata, hingga akhirnya Dasarata menikahi Dewi Kekayi dan memiliki anak bernama Bharata. Dewi Kekayi dijanjikan oleh Dasarata akan diberikan tahta untuk putranya di negara Ayodya karena menyelamatkan nyawa Prabu Dasarata. Pernikahan Dewi Kekayi dengan Dasarata tersebut ditransformasikan ke dalam cerpen oleh pengarang. Berikut kutipannya.

“...Aku merasa, aku telah melakukan banyak hal untuk membuat pilihan hidupku menjadi impianku sebagai perempuan muda. Melahirkan raja-raja. Hidup sejahtera. Mendapatkan lelaki yang bisa mengangkat statusku makin tinggi, kalau bisa melebihi status sosial dan ekonomi seluruh perempuan yang ada di negeri ini. Sejak haid pertama, aku melakukan tapa. Memohon pada para Dewa. Sudah lama aku tidak menyentuh daging. Aku memutih. Semuanya kulakukan untuk hidupku sendiri!" (Rusmini, 2017).

Perubahan watak juga terjadi pada tokoh Dasarata. Dalam cerita, Dasarata merupakan raja yang bijaksana. Namun, pengarang mengubah watak Dasarata di dalam cerpen melalui penggambaran tokoh Kekayi.

“... Aku tak paham berbagi gairah dengan lelaki. Yang merobek tubuhku dan melukaiku adalah Dasarata, lelaki tua yang begitu mabuk pada kemudaanku. Kecantikanku. Dia lebih cocok menjadi kakekku dibanding menjadi suamiku. Aku tidak pernah merasakan apa pun saat bersamanya. Bahkan ketika kami bersenggama, rasa sakit melumuri seluruh tulang-tulang dan urat dalam tubuhku. Tak sepotong manusia pun dititipkan di rahimku oleh lelaki tua bangka itu! Nafsunya yang menggebu telah melunturkan hasratku, lelaki tua itu tidak akan mampu menitipkan benih di rahimku. Berhari-hari aku harus melayaninya. Dia tidak peduli seluruh tubuhku sakit. Untungnya para Dewa tahu diri. Sejak haid pertama sampai disunting Dasarata, aku memilih tetap dalam tapa, memutih. Tidak makan apa pun selain nasi putih dan air putih" (Rusmini, 2017).

Pada kutipan cerpen di atas, Dasarata digambarkan sebagai laki-laki tua yang hanya menginginkan kepuasan seksual terhadap perempuan muda-dalam hal ini adalah Kekayi. Kekayi merasa bahwa dirinya harus melayani Dasarata setiap hari, dan tidak peduli dengan kondisi fisik Kekayi. Namun, dalam kutipan di atas, pengarang tidak mengubah pakem watak Dewi Kekayi yang memiliki ambisi untuk menghasilkan keturunan raja. Pengarang tetap mempertahankan watak Dewi Kekayi dalam tokoh Kekayi. Pada kutipan di atas, digambarkan tokoh Kekayi bersedia melayani nafsu Dasarata dengan hanya agar keinginannya terwujud, yaitu menghasilkan keturunan raja.

Pemertahanan watak tokoh juga dilakukan oleh pengarang pada watak tokoh Bharata. Tokoh Bharata-dalam cerita Ramayanaadalah anak Dewi Kekayi dan Dasarata. Ambisi 
Dewi Kekayi untuk menghasilkan keturunan raja mendapatkan titik cerah pada saat penobatan Ramawijaya - putra Dasarata dengan Dewi Kusalya. Prabu Dasarata diminta untuk mengusir Ramawijaya dari Ayodya oleh Dewi Kekayi. Akhirnya, Prabu Dasarata mengabulkan permintaan Dewi Kekayi tersebut. Akan tetapi, Bharata meminta agar dirinya menjadi raja sementara sambil menunggu Ramawijaya kembali ke Ayodya. Setelah Dasarata wafat, rakyat Ayodya marah dan menghujat Dewi Kekayi, termasuk Bharata, atas tindakan yang dilakukan Dewi Kekayi tersebut. Bagian cerita tersebut ditransformasikan ke dalam cerpen secara utuh oleh pengarang.

"Akuingin dicintai secara tulus oleh orangorang yang telah kubesarkan. Manusiamanusia yang tumbuh dalam tubuhku. Kupelihara dengan rasa sakit. Apakah Bharata tahu itu? Apakah Bharata tahu sulitnya menjadi perempuan? Sulitnya menjadi ibu? Sulitnya memeliharanya di dalam kandunganku, di tubuhku! Orangorang yang tumbuh dalam tubuhku telah melukai pengorbananku sebagai Kekayi. Bharata anak lelakiku menolak jadi raja. Dan memakiku dengan kata-kata kotor." "Kau tidak cocok jadi ibuku. Jika aku boleh memilih, aku tidak ingin mengeram dalam tubuhmu, Kekayi! Aku malu punya ibu culas macam kau! Ibu yang menginginkan hak yang bukan menjadi haknya. Ibu yang menghancurkan anaknya sendiri karena keinginannya yang tidak masuk akal. Aku menyesal dan mengutuk diriku sebagai manusia! Karena terlahir dari rahimmu. Kau telah membuat hidupku penuh bencana karena ambisimu. Kau telah melukai dan menistakan hidupmu dan hidup anakanakmu. Kerajaan ini adalah milik Rama. Bukan milikku. Kau lihat sendiri di luar sana. Rakyat menatapku dengan tatapan aneh. Tatapan penuh iba. Sekaligus benci. Kau telah membuatku menjadi anak yang tidak berbakti! Anak yang dilecehkan sepanjang hidupku. Karena aku memiliki ibu sepertimu. Aku menyesal menjadi anakmu!" (Rusmini, 2017).

Pada kutipan di atas, pengarang tetap mempertahankan sikap Bharata yang tidak ingin menjadi raja. Bharata ikut menghujat Kekayi yang telah melakukan tindakan demi mencapai ambisi. Dia menganggap bahwa kerajaan adalah milik Rama-dalam cerita Ramayana bernama Ramawijaya. Namun, pengarang menggambarkan bahwa sosok Bharata juga mengalami perlakuan buruk selama menjadi raja akibat perbuatan ibunya.

\section{PENUTUP}

Dari hasil penelitian menunjukkan bahwa cerita Dewi Kekayi dalam epos Ramayana dijadikan hiprogram cerpen Kekayi oleh Oka Rusmini melalui transformasi cerita. Dalam proses transformasi, pengarang mengembangkan cerita asal (sebagai hipogram) di dalam cerita baru.

Transformasi pada aspek penokohan terlihat pada penggunaan hipogram namanama tokoh wayang dalam Ramayana, seperti tokoh Kekayi, Dasarata, Kekaya, Bharata, dan Rama.Transformasi pada aspek latar terlihat pada penggunaan hipogram nama kerajaan, misalnya Kerajaan Padnapura, sedangkan transformasi pada aspek alur terlihat pada hipogram hubungan kekerabatan dari para tokoh. Hubungan kekerabatan antara Kekayi dan Bharata sebagai ibu dan anak; Kekaya dan Kekayi sebagai ayah dan anak angkat; Dasarata dan Kekayi sebagai sumai dan istri; Rama sebagai pemilik kerajaan Padnapura.

Pengarang juga mendekonstruksi cerita dengan melakukan beberapa perubahan pakem terhadap watak tokoh Kekayi, Dasarata, dan saudara angkat Kekayi. Sebaliknya, transformasi alur tidak diubah dan masih dipertahankan oleh pengarang sebagaimana alur di dalam cerita Ramayana. 


\section{DAFTAR PUSTAKA}

Abdullah, I. T. (1991) Aspek Intertekstualitas dalam Cerita Rakyat Data: Cerita Si Miskin dengan Raja Bayan. Humaniora, 3 (1), 98-132. Retrieved from https:// jurnal.ugm.ac.id/jurnal-humaniora/ article/view/2081. Diakses 20 Februari 2018.

Al-Mar'ruf, A. I. (2005) Intertekstualitas Puisi "Padamu Jua" Amir Hamzah dan Puisi "Doa" Chairil Anwar: Menelusuri "Cahaya" al-Qur'an dalam Puisi Sufistik Indonesia. Kajian Linguistik dan Sastra, 17 (32), 75-87. https://doi.org/10.23917/ kls.v17i1.4499. Diakses 5 Februari 2018.

Culler, J. (2002), Structuralist Poetics; Structuralism, Linguistics, and the Study of Literature. London: Routledge.

Culler, J. (2005), The Pursuit of Sign. London: Routledge.

Dewi, T. K. S. (2013) Arok Dedes dan Pararaton: Transformasi dan Dinamika Sastra dalam Wacana Globalisasi Sastra. Atavisme, 16(1), 119-128. https://doi.org/10.24257/ atavisme.v16i1.87.119-128. Diakses 20 Januari 2018.

Inarti, S. (2016) Analisis Intertekstual Puisi "Dongeng Sebelum Tidur" Karya Goenawan Mohamad. Metasastra: Jurnal Penelitian Sastra, 6(1), 81-89. https://doi. org/10.26610/metasastra.2013.v6i1.8189. Diakses 5 Januari 2018.

Nurgiyantoro, B. (1998) Transformasi Penokohan Tokoh Wayang dalam Fiksi Indonesia. Jurnal Penelitian Humaniora, 3(3), 125-144. Diakses dari https:// journal.uny.ac.id/index.php/humaniora/ article/view/5281/4580. Diakses 5 Januari 2018.
Nurgiyantoro, B. (2016) Transformasi Cerita Wayang dalam Novel Amba dan Pulang. Litera, 15(2), 201-216. https://doi. org/10.21831/1tr.v15i2.11823. Diakses 5 Januari 2018.

Rahayu,L.(2018) Transformasi Ideologi Legenda Gunung Tangkuban Parahu ke dalam Drama Sangkuriang Dayang Sumbi dan Sang Kuriang Karya Utuy Tatang Sontani. Sawerigading, 24(1),97108.doi:http://dx.doi.org/10.26499/ sawer.v24i1.283. Diakses 3 Februari 2018.

Riffaterre, M. (1978), Semiotics of Poetry. Blomington: Indiana University Press.

Rokhmansyah, A. (2014), Studi dan Pengkajian Sastra: Perkenalan Awal terhadap Ilmu Sastra. Yogyakarta: Graha Ilmu.

Rusmini, O. (2017, Februari). Kekayi. Jawa Pos, hlm. 7.

Supriadi, A., \& Ahmad, M. (2017) Transformasi Akhlak Nabi dalam Novel Ayat-Ayat Cinta. Sawerigading, 23(2), 263-273. doi:http://dx.doi.org/10.26499/sawer. v23i2. 265. Diakses 10 Februari 2018.

Sungkowati, Y. (2010) Dialog Antarteks Toenggoel dan Ronggeng Dukuh Paruk: Melawan atau Mengukuhkan Tradisi. Bahasa dan Seni: Jurnal Bahasa, Sastra, Seni, dan Pengajarannya, 38(1), 74-83. Diakses dari http://journal2.um.ac.id/ index.php/jbs/article/view/57. Diakses 6 Februari 2018.

Uniawati, N. (2017) Transformasi Sosial Drama Bawang Putih, Bawang Merah + Bawang Bombai. Sawerigading, 19(2), 217--226. doi: http://dx.doi.org/10.26499/sawer.v1 9i2.442. Diakses 7 Januari 2018. 